\title{
ORIGINAL ARTICLE Zinc protoporphyrin/heme ratio as parameter of iron status in moderately preterm infants: natural course and associations in the first 4 months
}

\author{
CG de Waal ${ }^{1,2}$, L Uijterschout ${ }^{1,3}$, M Abbink $^{4}$, B Boersma ${ }^{4}$, P Vos $^{5}$, WW Rövekamp ${ }^{1}$, F Hudig ${ }^{6}$, MD Akkermans ${ }^{1}$, JB van Goudoever ${ }^{2,7}$ and $^{2}$ \\ F Brus $^{1}$
}

OBJECTIVE: To determine the natural course of zinc protoporphyrin/heme ratio $(\mathrm{ZnPP} / \mathrm{H})$ and its role in the detection of iron deficiency (ID) and iron-deficiency anemia (IDA) in the first 4 months of life in moderately preterm infants.

STUDY DESIGN: ZnPP/H was measured at 1 week, 6 weeks and 4 months postnatal age in a prospective cohort of 161 Dutch infants born at a gestational age of $32+0$ to $36+6$ weeks who did not receive an erythrocyte transfusion or iron supplementation. RESULTS: ZnPP/H levels decreased in the first 6 weeks and increased thereafter. At 4 months postnatal age, ZnPP/H was higher in the 11 (8.5\%) infants with IDA (mean (s.d.): 260.8 (16.1)) but not in the 27 (21.3\%) infants with ID (mean (s.d.): 177.0 (15.1)) compared with normal infants (mean (s.d.): 157.3 (12.5)).

CONCLUSION: In moderately preterm infants, $\mathrm{ZnPP} / \mathrm{H}$ can be of additional value to detect infants at risk for IDA due to iron-deficient erythropoiesis at 4 months of age.

Journal of Perinatology (2017) 37, 690-694; doi:10.1038/jp.2017.3; published online 9 February 2017

\section{INTRODUCTION}

Preterm infants are prone to develop iron deficiency (ID) and irondeficiency anemia (IDA) in the first 4 months of life due to lower iron stores at birth compared with term infants, rapid growth and iron losses by phlebotomy after birth. ${ }^{1,2}$ ID, even without anemia, may cause irreversible morbidity in preterm infants, such as impaired neurological development. ${ }^{3}$ Iron supplementation is therefore recommended in preterm infants with a birth weight $<1800 \mathrm{~g}^{4,5}$ However, these recommendations are mostly based on studies in infants born at $<32$ weeks of gestational age (GA). Information on iron requirements in moderately preterm infants born at 32-37 weeks GA, accounting for the greater relative proportion of preterm births, is limited. 2,6,7

Providing iron supplementation in each preterm infant, regardless of its iron status, might cause iron overload in infants with sufficient iron stores, which is associated with an increased risk of infection and impaired growth. ${ }^{1,8}$ To be able to individualize iron supplementation in moderately preterm infants, it is important to differentiate infants at risk for ID and those who are not and might be harmed by iron overload.

Early recognition of moderately preterm infants at risk for ID is a clinical challenge. Ferritin is a widely used parameter representing body iron stores, but its interpretation can be difficult as it increases during infection and inflammation. ${ }^{9}$ The zinc protoporphyrin/heme ratio $(\mathrm{ZnPP} / \mathrm{H})$ may be a reliable alternative to screen for ID because it is not influenced by acute inflammation. ${ }^{10,11} \mathrm{ZnPP} / \mathrm{H}$ is an indicator of iron-restricted erythropoiesis. Without sufficient amounts of iron available, zinc will be incorporated in protoporphyrin IX in red blood cells, causing an increase in ZnPP/H levels. ${ }^{11-13}$
As moderately preterm infants are at risk to develop ID and IDA in the first 4 months of life, one might expect increasing $\mathrm{ZnPP} / \mathrm{H}$ levels after birth. However, the natural course of $\mathrm{ZnPP} / \mathrm{H}$ in the first months of life and the association of $\mathrm{ZnPP} / \mathrm{H}$ with the development of ID and IDA is not known in these infants. Therefore, we addressed the following questions in a cohort of Dutch moderately preterm infants screened for ID and IDA, who did not receive an erythrocyte transfusion or iron supplementation: (1) What is the natural course of $\mathrm{ZnPP} / \mathrm{H}$ in the first 4 months of life? (2) Are $\mathrm{ZnPP} / \mathrm{H}$ levels higher in moderately preterm infants with ID or IDA at 4 months of age compared with those who are not iron deficient? (3) What is the influence of demographical and clinical neonatal and maternal factors, which might have a negative impact on the iron status of the newborn infants, on the level of $\mathrm{ZnPP} / \mathrm{H}$ at 4 months of age? (4) Are higher ZnPP/H levels associated with lower hemoglobin $(\mathrm{Hb})$ and ferritin concentrations and higher reticulocyte counts at 4 months of age?

\section{METHODS}

Study design and population

A prospective cohort study on iron status in moderately preterm infants born between $32+0$ and $36+6$ weeks GA was conducted in three level II hospitals in the Netherlands. ${ }^{14}$ Eligible infants were identified from delivery records. Exclusion criteria were congenital malformations, chronic or inherited metabolic diseases, hemoglobinopathies, active blood loss during delivery/major bleeding, twin-to-twin transfusion syndrome, hemolytic disease or erythrocyte transfusions in the first 4 months of life. Pediatricians were allowed to prescribe iron supplementation if they considered this to be appropriate. Infants receiving iron supplementation

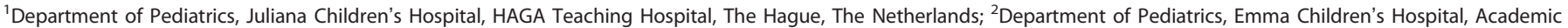

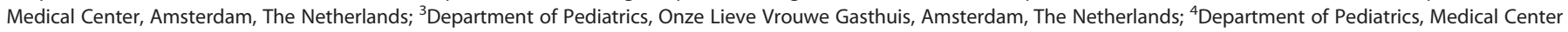

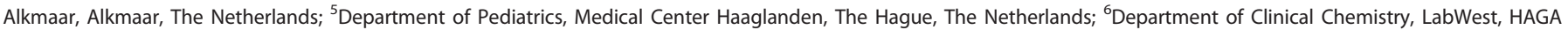

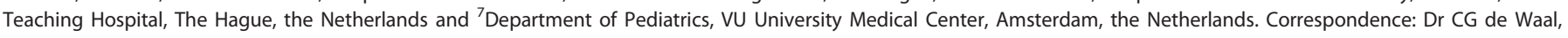
Department of Pediatrics, Emma Children's Hospital, Academic Medical Center, P.O. Box 22660, Amsterdam 1100 DD, The Netherlands.

E-mail: c.g.dewaal@amc.nl

Received 6 July 2016; revised 6 January 2017; accepted 12 January 2017; published online 9 February 2017 


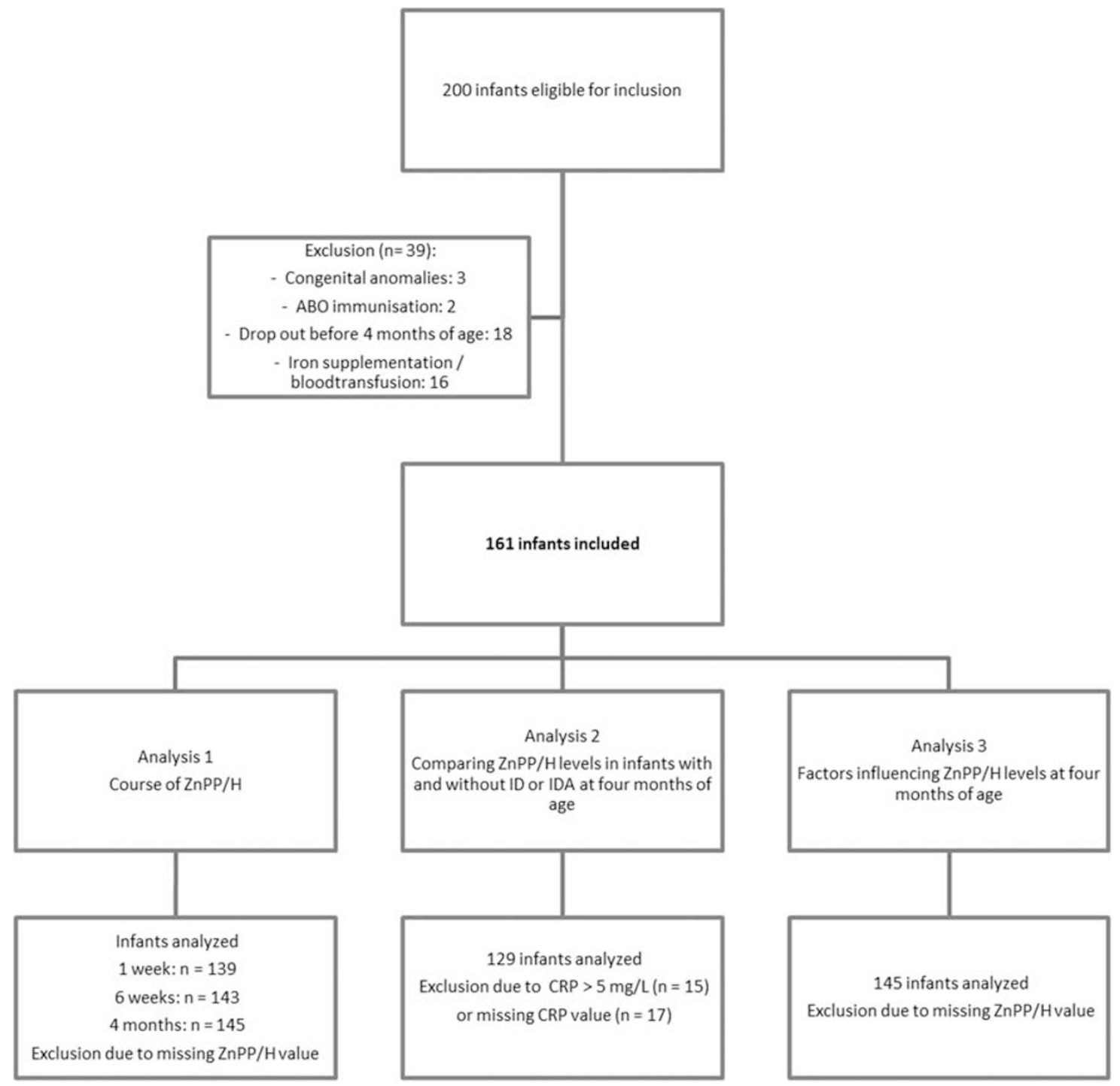

Figure 1. Flow chart of study population and the number of infants included in the analyses. Reasons for drop-out before 4 months of age: moved $(n=4)$; did not came to the routine checks in the outpatient clinic $(n=3)$; parents withdrew consent to draw extra blood for study purposes $(n=9)$, and unknown $(n=2)$. CRP, C-reactive protein; ID, iron deficiency; IDA, iron-deficiency anemia; ZnPP/H, zinc protoporphyrin/ heme ratio.

were not included in the analyses. The relation between $\mathrm{ZnPP} / \mathrm{H}$ levels and ID and IDA was studied in infants who had normal C-reactive protein (CRP) concentrations $\left(<5 \mathrm{mg} \mathrm{I}^{-1}\right)$ because the diagnoses of ID and IDA were based on ferritin concentrations, an acute-phase protein that might be elevated during infection or inflammation. Written informed consent was obtained from all parents of the infants included. The study was approved by the Medical Ethics Committee of South-West Holland.

\section{Data collection}

Venous blood $(3 \mathrm{ml})$ was collected in the first week of life and at routine follow-up visits at the postnatal age of 6 weeks and 4 months. These blood samples were analyzed for $\mathrm{ZnPP} / \mathrm{H}, \mathrm{Hb}$, ferritin, reticulocyte count and CRP.

Information on maternal conditions that might have a negative influence on the iron status of the newborn infants (gestational diabetes, pregnancy-induced hypertension, smoking habits and iron supplementation during pregnancy) $)^{15,16}$ was collected from medical files. Gestational diabetes was diagnosed based on an abnormal oral glucose test when fasting plasma glucose was $\geqslant 7.0 \mathrm{mmol}^{-1}\left(126 \mathrm{mg} \mathrm{dl}^{-1}\right)$ or $2 \mathrm{~h}$ plasma glucose was $\geqslant 11.1 \mathrm{mmoll}^{-1}\left(200 \mathrm{mg} \mathrm{dl}^{-1}\right) .{ }^{17}$ Pregnancy-induced hypertension was defined as a blood pressure of $>140 \mathrm{~mm} \mathrm{Hg}$ systolic or $>90 \mathrm{~mm} \mathrm{Hg}$ diastolic, either of those measured at least twice after the twentieth week of gestation in women with normal blood pressures before pregnancy. ${ }^{18}$ Postnatal data of the infants (Apgar scores, birth weight, GA, neonatal diagnoses and feeding practices) were collected from medical files. Infants were identified as small for GA when their birth weight was less than the 10th percentile using Dutch references. ${ }^{19}$ Anthropometric data were recorded after birth and when visiting the outpatient clinic for routine follow-up. Growth rate at follow-up visits was calculated as weight gain in grams relative to birth weight (growth rate= weight at 4 months/ birth weight).

\section{Definitions}

ID at the age of 4 months was defined as a ferritin concentration $<20 \mu \mathrm{gl}^{-1}$. IDA was defined as ID in combination with anemia: $\mathrm{Hb}<105 \mathrm{~g} \mathrm{I}^{-11,20}$ Infants described as normal had neither ID nor IDA. ZnPP/H was displayed as micromol mol ${ }^{-1}$ heme; no reference values were available.

\section{Biochemical tests}

$\mathrm{Hb}$ and reticulocyte count were determined using a Sysmex XE-2100 (Sysmex Corporation, Kobe, Japan) automated hematology analyzer. Ferritin and CRP concentrations were analyzed in plasma, using a Unicel Dxl 800 immunochemistry analyzer (Beckman Coulter, Fullerton, CA, USA). $\mathrm{ZnPP} / \mathrm{H}$ was analyzed in whole blood after washing with phosphate- 
Table 1. Characteristics of the study population

Infant characteristics

Gestational age (weeks)

Birth weight $(\mathrm{g})$

Small for gestational age

Gender (male)

Apgar score at $5 \mathrm{~min}$

Breastfeeding

Growth in the first 4 months of life

(times birth weight)

ID at 4 months of age

IDA at 4 months of age

Maternal characteristics

Smoking during pregnancy

Hypertension

Gestational diabetes

Iron supplementation during pregnancy

Abbreviations: ID, iron deficiency; IDA, iron-deficiency anemia. Values are mean (s.d.) or number (\%). Maternal characteristics are based on McLimore et al. $^{15}$ and Siddappa et al. ${ }^{16}$

buffered saline by using the AVIV ZPP Hematofluorometer model 206D (AVIV Biomedical, Lakewood, NJ, USA). The interassay variation on the normality cutoff value is $4.4 \%$ and the intra-assay variation is $5.6 \%$ for this analyzer.

\section{Statistical analysis}

Statistical analyses were performed by using SPSS (version 22; SPSS, Chicago, IL, USA). In this paper, we describe subanalyses of a study to evaluate iron status and the incidence of ID and IDA in preterm infants. ${ }^{14}$ The study was not specifically powered to detect changes in $\mathrm{ZnPP} / \mathrm{H}$ levels. Outcome variables were checked for normality using histograms and the Kolmogorov-Smirnov test. ZnPP/H and ferritin levels were not normally distributed and therefore logarithmic transformation of these parameters was used to calculate the mean and s.d. When describing the results, the outcomes of transformed variables were converted back to their original units.

To compare the $\mathrm{ZnPP} / \mathrm{H}$ levels between infants with ID or IDA and normal infants at 4 months of age, we used the Student's independent $T$-test or the Mann-Whitney $U$-test, depending on the distribution of the data. Subsequently, in case of a difference in $\mathrm{ZnPP} / \mathrm{H}$ levels between infants with ID or IDA and normal infants, a receiver operating characteristic curve was constructed to look for a cutoff value of $\mathrm{ZnPP} / \mathrm{H}$ at 1 week of age predictive of the risk to develop ID or IDA at 4 months of age.

At 4 months of age, we analyzed demographical and clinical factors as well as laboratory parameters that possibly influence ZnPP/H levels. ${ }^{12,21}$ First, a linear univariate regression analysis was carried out for the following factors: (1) infant factors: GA, birth weight, gender, Apgar score at 5 min of age, growth rate at 4 months of age, and duration of breastfeeding, (2) maternal factors: smoking during pregnancy, pregnancy-induced hypertension, gestational diabetes, and iron supplementation during pregnancy, and (3) iron status parameters: $\mathrm{Hb}$, reticulocyte count, and ferritin. Second, in multivariate analysis with a backward Wald method, we included the demographical and clinical factors and laboratory parameters associated with $\mathrm{ZnPP} / \mathrm{H}$ in univariate analysis with a $P$-value $<0.10$.

Statistical significance was defined as a $P$-value $<0.05$.

\section{RESULTS}

Study population

Of the 200 infants eligible for inclusion, 39 infants were excluded (Figure 1). Characteristics of the remaining 161 infants included in the study are shown in Table 1. Mean GA at birth was 34.9 (s.d. 1.1) weeks and mean birth weight was 2,297 (s.d. 459) $\mathrm{g}$.

Three different analyses were performed to answer the four research questions. Figure 1 shows the number of infants included in these analyses.

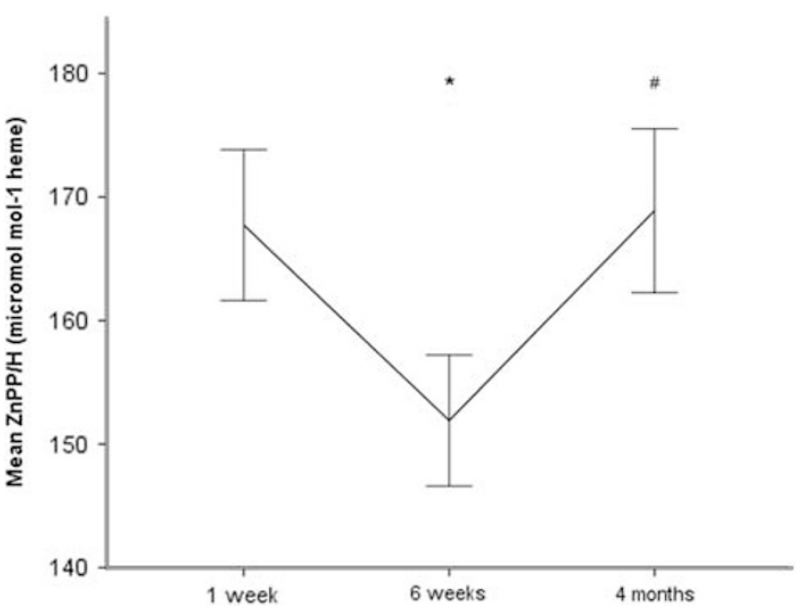

Figure 2. Mean zinc protoporphyrin/heme ratio $(\mathrm{ZnPP} / \mathrm{H}$; micromol mol ${ }^{-1}$ heme) levels at different postnatal ages. Error bars represent s.e.m. ${ }^{*} P<0.05$, comparison of week 1 with week 6 . ${ }^{\#} P<0.05$, comparison of week 6 and 4 months.

Natural course of $\mathrm{ZnPP} / \mathrm{H}$

Figure 2 shows the course of $\mathrm{ZnPP} / \mathrm{H}$ at three time points in the first 4 months of life in the study population. After an initial decline between the first and sixth week of life $(P<0.01), \mathrm{ZnPP} / \mathrm{H}$ levels increased between 6 weeks and 4 months of age $(P=0.036)$.

Comparing ZnPP/H levels in infants with ID or IDA and normal infants

At 4 months of age, after excluding infants with $C R P>5 \mathrm{mg} \mathrm{I}^{-1}$ $(n=15)$ or a missing CRP value $(n=17), 129$ infants were analyzed for ID and IDA. ID was present in 27 (21.3\%) infants and IDA in 11 (8.5\%) infants (Table 1).

$\mathrm{ZnPP} / \mathrm{H}$ levels were higher in infants with IDA compared with normal infants (mean (s.d.): 260.8 (16.1) versus 153.9 (12.2), $P<0.001)$ at 4 months of age. At the same time point, no difference in $\mathrm{ZnPP} / \mathrm{H}$ levels was found in infants with ID compared with normal infants (mean (s.d.): 177.0 (15.1) versus 157.3 (12.5), $P=0.223$ ).

$A$ receiver operating characteristic curve was constructed for $\mathrm{ZnPP} / \mathrm{H}$ levels at 1 week of age and IDA at the age of 4 months. The area under the curve was 0.7 (95\% confidence interval: $0.5-0.8)$ with a $P$-value of 0.11 and the most optimal cutoff value would be a $\mathrm{ZnPP} / \mathrm{H}$ level of 187.5 micromol mol ${ }^{-1}$ heme with a sensitivity of $60 \%$ and specificity of $78 \%$. (Figure 3 ) With this cutoff value, the positive predicting value is $21.6 \%$ and the negative predicting value is $95.4 \%$.

Factors influencing ZnPP/H levels at 4 months of age Results of linear regression analyses of demographical and clinical factors and laboratory parameters possibly influencing $\mathrm{ZnPP} / \mathrm{H}$ levels at 4 months of age are presented in Table 2. Multivariate analyses showed that ZnPP/H levels were positively associated with growth rate in the first 4 months. Infants of mothers with hypertension during pregnancy had lower $\mathrm{ZnPP} / \mathrm{H}$ levels at 4 months of age compared with infants of mothers with no pregnancy-induced hypertension. Furthermore, infants with lower $\mathrm{Hb}$ levels had significantly higher $\mathrm{ZnPP} / \mathrm{H}$ levels. However, no associations between ferritin and reticulocyte count with $\mathrm{ZnPP} / \mathrm{H}$ levels were found at 4 months of age. In addition, $\mathrm{ZnPP} / \mathrm{H}$ and CRP levels were not associated in our study population.

\section{DISCUSSION}

In this study, we describe the natural course of $\mathrm{ZnPP} / \mathrm{H}$ during the first 4 months of life in a cohort of Dutch moderately preterm 


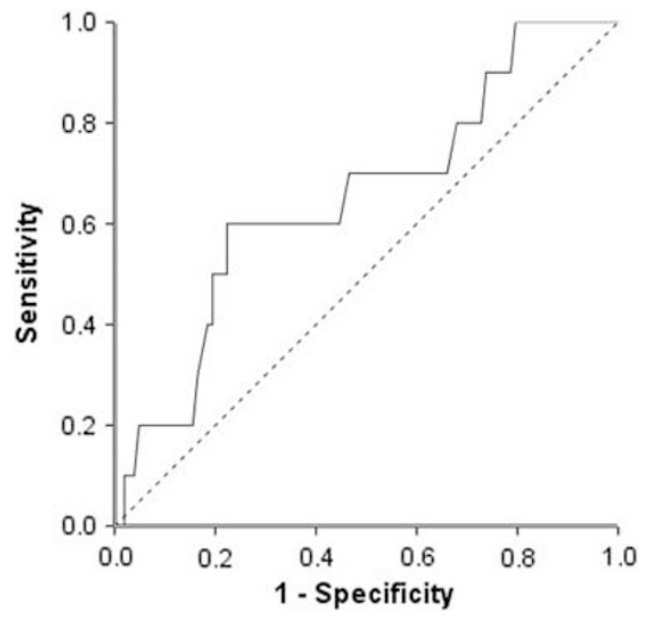

Figure 3. Receiver operating characteristic curve for zinc protoporphyrin/heme ratio levels at 1 week of age in infants with irondeficiency anemia.

infants who did not receive an erythrocyte transfusion or iron supplementation. ZnPP/H levels show an initial decline between 1 week and 6 weeks of age and an increase between 6 weeks and 4 months of age. Furthermore, at the age of 4 months $\mathrm{ZnPP} / \mathrm{H}$ levels were higher in the 11 (8.5\%) infants with IDA compared with normal infants. However, no differences in $\mathrm{ZnPP} / \mathrm{H}$ were observed in the $27(21.3 \%)$ infants with ID without anemia and normal infants. At 4 months of age, higher ZnPP/H levels were associated with a higher growth rate and lower $\mathrm{Hb}$ levels. In addition, maternal hypertension during pregnancy was associated with lower $\mathrm{ZnPP} / \mathrm{H}$ levels at 4 months of age.

\section{Natural course of $\mathrm{ZnPP} / \mathrm{H}$}

As $\mathrm{ZnPP} / \mathrm{H}$ is an indicator of iron available for erythropoiesis, ${ }^{12,13}$ one would expect an increase in $\mathrm{ZnPP} / \mathrm{H}$ levels after birth representing higher iron needs due to rapid growth and iatrogenic iron losses due to frequent blood sampling. However, we found a decrease in $\mathrm{ZnPP} / \mathrm{H}$ levels in the first 6 weeks that returned to baseline levels thereafter. The initial decrease in $\mathrm{ZnPP} / \mathrm{H}$ levels could be explained by the breakdown of fetal $\mathrm{Hb}$. It is known that healthy term infants have sufficient amounts of iron available due to the recirculation of iron derived from fetal $\mathrm{Hb}$, until their birth weight has doubled at 6 months of age. In our study population, birth weight has already doubled at 6 weeks of age with a simultaneous decrease of iron available for erythropoiesis and a subsequent increase of $\mathrm{ZnPP} / \mathrm{H}$ levels from 6 weeks of age onwards.

The natural course of $\mathrm{ZnPP} / \mathrm{H}$ in our study differs from that described by Griffin et al. ${ }^{22}$ They found a gradual decline of $\mathrm{ZnPP} / \mathrm{H}$ in the first year of life in preterm, low birth weight infants. However, $40 \%$ of the infants included in that study received an erythrocyte transfusion. Erythrocyte transfusions decrease $\mathrm{ZnPP} / \mathrm{H}$ levels ${ }^{11,12}$ and this might explain the different course of $\mathrm{ZnPP} / \mathrm{H}$ in the study of Griffin et al. ${ }^{22}$ compared with our study.

We have found that $\mathrm{ZnPP} / \mathrm{H}$ levels measured in the first week of life were higher than $\mathrm{ZnPP} / \mathrm{H}$ levels in the cord blood of a comparable cohort of preterm infants. ${ }^{23}$ The higher $\mathrm{ZnPP} / \mathrm{H}$ levels in our study population might be a reflection of intrauterine growth restriction, intrauterine hypoxia and maternal conditions that can lead to impaired placental function with decreased mother-to-fetus iron supply. Insufficient iron supply to the fetus stimulates erythropoiesis and increases $\mathrm{ZnPP} / \mathrm{H}$ levels. ${ }^{15,16}$ In the study by Lorenz et al., ${ }^{23}$ infants who were exposed to these prenatal conditions were excluded.
Table 2. Linear regression analyses of factors influencing $\mathrm{ZnPP} / \mathrm{H}$ levels at 4 months of age $(n=145)$

\begin{tabular}{|c|c|c|c|c|}
\hline & \multicolumn{2}{|c|}{$\begin{array}{l}\text { Univariate } \\
\text { analyses }\end{array}$} & \multicolumn{2}{|c|}{$\begin{array}{l}\text { Multivariate } \\
\text { analyses }^{\mathrm{a}}\end{array}$} \\
\hline & Beta & P-value & Beta & P-value \\
\hline \multicolumn{5}{|l|}{ Infant factors } \\
\hline Gestational age (weeks) & -0.2 & 0.01 & -0.1 & 0.362 \\
\hline Birth weight $(\mathrm{g})$ & -0.2 & 0.04 & 0.1 & 0.349 \\
\hline Gender (male) & -0.1 & 0.498 & & \\
\hline Breastfeeding (weeks) & -0.1 & 0.108 & & \\
\hline $\begin{array}{l}\text { Growth in the first } 4 \text { months } \\
\text { (\% relative to birth weight) }\end{array}$ & 0.3 & 0.002 & 0.3 & 0.000 \\
\hline \multicolumn{5}{|l|}{ Maternal factors } \\
\hline Smoking & 0 & 0.895 & & \\
\hline Pregnancy-induced hypertension & -0.1 & 0.095 & -0.2 & 0.027 \\
\hline Gestational diabetes & 0.1 & 0.487 & & \\
\hline \multicolumn{5}{|l|}{ Iron status parameters } \\
\hline Ferritin (log) & -0.1 & 0.113 & & \\
\hline Reticulocyte count & 0.1 & 0.305 & & \\
\hline $\mathrm{Hb}$ & -0.3 & 0.002 & -0.3 & 0.001 \\
\hline CRP & -0.1 & 0.368 & & \\
\hline
\end{tabular}

Abbreviations: CRP, C-reactive protein; $\mathrm{Hb}$, hemoglobin; $\mathrm{ZnPP} / \mathrm{H}$, zinc

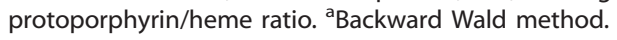

Comparing $\mathrm{ZnPP} / \mathrm{H}$ levels in infants with ID or IDA and normal infants

We have showed that infants diagnosed with IDA at 4 months of age had higher levels of $\mathrm{ZnPP} / \mathrm{H}$. As described in other studies, no association was observed between high $\mathrm{ZnPP} / \mathrm{H}$ levels and low ferritin levels in infants with ID but without anemia. ${ }^{22} \mathrm{~A}$ possible explanation for the absence of an association with ferritin is that $\mathrm{ZnPP} / \mathrm{H}$ directly reflects the amount of iron available for the erythropoiesis, whereas ferritin represents the amount of stored iron in the body. ZnPP/H seems to be a good representative of iron available for erythropoiesis, but it is not useful as an indicator of iron stores.

Factors influencing $\mathrm{ZnPP} / \mathrm{H}$ levels at 4 months of age As expected, $\mathrm{ZnPP} / \mathrm{H}$ levels were higher at 4 months of age in faster growing infants. High growth velocity has been reported as a risk factor for ID and IDA, ${ }^{1,23}$ because an increase in weight and subsequently expanding blood volume increases the requirement of iron for erythropoiesis. ${ }^{12,21}$

We found lower $\mathrm{ZnPP} / \mathrm{H}$ levels in the infants of mothers with pregnancy-induced hypertension. One could expect higher $\mathrm{ZnPP} / \mathrm{H}$ levels because of insufficient iron transport due to pathophysiological changes in the placenta that have been described in the mothers with hypertension during pregnancy. On the other hand, similar changes of the placenta may cause chronic intrauterine hypoxia and an increased erythropoiesis in the fetus. ${ }^{16}$ Higher $\mathrm{Hb}$ levels, which we found at 1 week of age in infants born to mothers with pregnancy-induced hypertension, probably reflect intrauterine hypoxia and increased erythropoiesis and might have contributed to the lower levels of $\mathrm{ZnPP} / \mathrm{H}$ in these infants at 4 months of age.

\section{Strengths and limitations}

To the best of our knowledge, this is the first study to describe the natural course of $\mathrm{ZnPP} / \mathrm{H}$ in the first 4 months of life in moderately preterm infants. Infants were diagnosed with ID or IDA at 4 months of age based on the World Health Organization criteria by taking CRP levels, and therefore inflammation, into account. 
The main limitation that needs to be addressed is the limited sample size of our population, which is further accentuated by missing data at the three time points that measurements were performed. The number of patients might therefore be too small to detect an association between $\mathrm{ZnPP} / \mathrm{H}$ and feeding practices, gestational diabetes, ferritin and reticulocyte count. On the other hand, relatively few of the eligible infants were omitted from the analysis that makes it more likely to apply our conclusions to a greater proportion of near-term premature infants. Although we did find higher $\mathrm{ZnPP} / \mathrm{H}$ levels in infants with IDA at 4 months of age, we were not able to determine reliable cutoff values for $\mathrm{ZnPP} / \mathrm{H}$ at 1 week of age to predict IDA at 4 months of age as can be seen in the receiver operating characteristic curve we constructed (Figure 3). This can be attributed to the limited number of patients with IDA in our cohort. In two previous publications on iron status parameters in the same infants, ${ }^{14,24}$ the predictive value of ferritin and hepcidin are described. Probably, a combination of iron status parameters is valuable to predict the risk for ID after birth. This is considered a topic for further research. Furthermore, larger studies are needed to investigate whether or not early ZnPP/H values are useful to predict ID or IDA at 4 months of age.

\section{CONCLUSION}

$\mathrm{ZnPP} / \mathrm{H}$ reflects iron available for erythropoiesis in the first 4 months of life in moderately preterm infants and can be of additional value to detect infants with IDA due to iron-deficient erythropoiesis at 4 months of age, even with sufficient iron stores. The value of early $\mathrm{ZnPP} / \mathrm{H}$ measurements to predict IDA at 4 months of age remains to be established.

\section{CONFLICT OF INTEREST}

The authors declare no conflict of interest.

\section{REFERENCES}

1 Domellöf M, Braegger C, Campoy C, Colomb V, Decsi T, Fewtrell M et al. Iron requirements of infants and toddlers. J Pediatr Gastroenterol Nutr 2014; 58(1): 119-129.

2 Long H, Yi J-M, Hu P-L, Li Z-B, Qiu W-Y, Wang F et al. Benefits of Iron supplementation for low birth weight infants: a systematic review. BMC Pediatr 2012; 12(1): 99.

3 Walker SP, Wachs TD, Grantham-Mcgregor S, Black MM, Nelson CA, Huffman SL et al. Inequality in early childhood: Risk and protective factors for early child development. Lancet 2011; 378(9799): 1325-1338.

4 Agostoni C, Buonocore G, Carnielli VP, De Curtis M, Darmaun D, Decsi T et al. Enteral nutrient supply for preterm infants: commentary from the European Society of Paediatric Gastroenterology, Hepatology and Nutrition Committee on Nutrition. J Pediatr Gastroenterol Nutr 2010; 50(1): 85-91.
5 Baker RD, Greer FR. Diagnosis and prevention of iron deficiency and irondeficiency anemia in infants and young children (0-3 years of age). Pediatrics 2010; 126(5): 1040-1050.

6 Berglund S, Westrup B, Domellöf M. Iron supplements reduce the risk of iron deficiency anemia in marginally low birth weight infants. Pediatrics 2010; 126(4): e874-e883.

7 Berglund SK, Westrup B, Hägglöf B, Hernell O, Domellöf M. Effects of iron supplementation of LBW infants on cognition and behavior at 3 years. Pediatrics 2013; 131(1): 47-55.

8 lannotti LL, Tielsch JM, Black MM, Black RE. Iron supplementation in early childhood: health benefits and risks. Am J Clin Nutr 2006; 84(6): 1261-1276.

9 Tomkins A. Assessing micronutrient status in the presence of inflammation. J Nutr 2003; 133(5 Suppl 2): 1649S-1655S.

10 Rettmer RL, Carlson TH, Origenes ML, Jack RM, Labb RF. Zinc protoporphyrin/ heme ratio for diagnosis of preanemic iron deficiency. Pediatrics 1999; 104(3): e37.

11 Winzerling JJ, Kling PJ. Iron-deficient erythropoiesis in premature infants measured by blood zinc protoporphyrin/heme. J Pediatr 2001; 139(1): 134-136.

12 Juul SE, Zerzan JC, Strandjord TP, Woodrum DE. Zinc protoporphyrin/heme as an indicator of iron status in NICU patients. J Pediatr 2003; 142(3): 273-278.

13 Metzgeroth G, Adelberger V, Dorn-Beineke A, Kuhn C, Schatz M, Maywald O et al. Soluble transferrin receptor and zinc protoporphyrin - competitors or efficient partners? Eur J Haematol 2005; 75(4): 309-317.

14 Uijterschout L, Domellöf M, Abbink M, Berglund SK, van Veen I, Vos P et al. Iron deficiency in the first 6 months of age in infants born between 32 and 37 weeks of gestational age. Eur J Clin Nutr 2015; 69(5): 598-602.

15 McLimore HM, Phillips AK, Blohowiak SE, Daphne Q, DQ-D Pham, Coe CL et al. Impact of multiple prenatal risk factors on newborn iron status at delivery. J Pediatr Hematol Oncol 2013; 35(6): 473-477.

16 Siddappa AM, Rao R, Long JD, Widness JA, Georgieff MK. The assessment of newborn iron stores at birth: a review of the literature and standards for ferritin concentrations. Neonatology 2007; 92(2): 73-82.

17 Lips J, Visser G, Peeters L, Al E. Richtlijn diabetes mellitus en zwangerschap. Ned Ver Obstet Gynaecol 2010. Available at: http://nvog-documenten.nl.

18 Mol B, Schuerman F, Van Lingen R, Al E. Richtlijn hypertensieve aandoeningen tijdens de zwangerschap. Ned Ver Obstet Gynaecol 2011 Available at: http://nvog-documenten.nl.

19 Schönbeck Y, Talma H, van Dommelen P, Bakker B, Buitendijk SE, HiraSing RA et al. The world's tallest nation has stopped growing taller: the height of Dutch children from 1955 to 2009. Pediatr Res 2013; 73(3): 371-377.

20 World Health Organisation. Assessing the Iron Status of Populations: Including Literature Reviews: Report of a Joint World Health Organization/Centers for Disease Control and Prevention Technical Consultation on the Assessment of Iron Status at the Population Level, WHO: Geneva, Switzerland, 2004.

21 Lott DG, Zimmerman MB, Labbé RF, Kling PJ, Widness JA. Erythrocyte zinc protoporphyrin is elevated with prematurity and fetal hypoxemia. Pediatrics 2005; 116(2): 414-422.

22 Griffin IJ, Reid MM, McCormick KPB, Cooke RJ. Zinc protoporphyrin/haem ratio and plasma ferritin in preterm infants. Arch Dis Child Fetal Neonatal Ed 2002; 87(1): F49-F51.

23 Lorenz L, Peter A, Poets CF, Franz AR. A review of cord blood concentrations of iron status parameters to define reference ranges for preterm infants. Neonatology 2013; 104(3): 194-202.

24 Uijterschout L, Domellöf M, Berglund S, Abbink M, Vos P, Rövekamp L et al. Serum hepcidin in infants born after 32 to 37 wk of gestational age. Pediatr Res 2016; 79(4): 608-613. 